\title{
Apoio à inovação em Sistemas de Informação: análise de projetos do PIPE - FAPESP (2010-2015)
}

\author{
Enio Borba Carli \\ Centro Universitário Fundação Santo André (CUFSA) \\ Santo André - SP - Brasil \\ enio.carliefsa.br
}

\begin{abstract}
This study analyzes the Information System projects that received support from FAPESP through the program "Innovative Research in Small Business" (PIPE) during 2010-2015. It is an exploratory research comprised of information collection, treatment and analysis. Each project was analyzed considering: the theme of the innovation proposed and its beneficiaries; the academic career of the project's researchers (responsible and fellows). It is a research aimed at expanding the knowledge about supporting iniciatives for technological innovation of Information Systems. The assessment of initiatives to promote technological innovation is a key to understanding its actors profile, the theme of the proposed challenges, the effectiveness of the adopted model innovation, and the economic and social return on investment in startups. The results indicate a diversity of themes in the projects and in the profile of the researchers, but with a strong concentration of researchers from USP. The open data base of FAPESP is a limiting factor in the analysis of supported and unsupported projects. The definition by FAPESP of a data access protocol for researchers is desirable and would contribute to more conclusive analyzes.
\end{abstract}

Resumo. Este estudo analisa os projetos de Sistema de Informação que receberam apoio da FAPESP por meio do programa "Pesquisa Inovativa em Pequenas Empresas" (PIPE) no período 2010-2015. É uma pesquisa exploratória com coleta, tratamento e analise da informação. Em cada projeto são analisados: a temática da inovação proposta e os seus beneficiários; a trajetória acadêmica dos pesquisadores do projeto (responsável e bolsistas). É uma pesquisa que visa ampliar o conhecimento de iniciativas de apoio a inovação tecnológica em Sistemas da Informação. Avaliar iniciativas em prol da inovação tecnológica é fundamental para compreender o perfil dos seus atores, a temática dos desafios propostos, a eficácia do modelo de apoio a inovação adotado, o retorno econômico e social do investimento em empresas nascentes. Os resultados indicam uma diversidade de temas nos projetos e no perfil dos pesquisadores, mas com uma forte concentração de pesquisadores oriundos da USP. A base aberta de dados da FAPESP é um fator limitador na análise dos projetos apoiados e não apoiados. A definição, pela FAPESP, de um protocolo de acesso a dados para pesquisadores é desejável e contribuiria para análises mais conclusivas. 


\section{Introdução}

Arquivos digitais de diferentes tamanhos e formatos são gerados incessantemente todos os dias indicando que a informação ocupa um lugar central na vida humana. Não obstante o avanço das tecnologias de informação e das facilidades de acessar e produzir informação, temos ainda muitos desafios que estão relacionados ao desenvolvimento de Sistemas de Informação (SI). Soluções a estes desafios do mundo digital são perseguidas de diferentes formas por diferentes agentes. As grandes empresas estão focando em oportunidades que representem um grande mercado, ou naqueles que embora sejam mais específicos, são muito lucrativos. Mas outros atores, fora das grandes empresas, estão bastante ativos e demonstram capacidade de criar soluções inovadoras que competem com as grandes empresas, muitas vezes por meio de modelos de negócio que tornam suas soluções mais acessíveis e impactantes. É extensa a relação de iniciativas de desenvolvimento de software que nasceram pequenas, mas após ganharem extensa popularidade e valorização, são disputadas e compradas em transações milionárias por grandes empresas. Pequenas empresas ou comunidades de desenvolvedores de programas de computadores demonstram capacidade de criar software e aplicativos que atendem as necessidades de diferentes setores da economia, da administração pública, ou do interesse da coletividade.

Parte importante das soluções destes desafios do mundo digital envolve o desenvolvimento de SI. É fácil constatar, diante da constante oferta de novos softwares e aplicativos que surgem a todo momento, que ainda existem inúmeras necessidades que não estão sendo atendidas ou que precisam ser melhor atendidas por SI. É neste ponto que a inovação é relevante!

A inovação tecnológica é hoje um tema central na economia globalizada. Diferentes estudos indicam que a falta de inovação tecnológica em uma empresa a coloca em desvantagem em relação as outras empresas que são capazes de inovar continuamente (CALMANOVICI, 2011) (BOGOSSIAN, 2012).

De forma geral, uma inovação é uma solução aperfeiçoada ou inédita que oferece resultados melhores que os anteriores ou supreendentemente novos, com ganhos inquestionáveis: no processo produtivo; no menor uso de materiais, energia e tempo; na eficiência e eficácia do processo; na satisfação com design e as funcionalidades; no modelo de negócio; no valor para o usuário final; na lucratividade para a empresa; na relação custo-benefício ao consumidor.

Deste modo, se no processo produtivo existe espaço para a melhoria no uso de materiais e energia (visando a redução de custos e a sustentabilidade ambiental), na redução do tempo (permitindo entregar mais rápido os produtos ou serviços), na eficiência de procedimentos operacionais e na eficácia da gestão, então existe espaço para a inovação. Da mesma forma, se a experiência envolvendo a satisfação com o produto ou serviço pode ser aperfeiçoada na forma de realizar o negócio, na percepção de conquista ao consumir, então existe espaço para a inovação. Existe também um enorme campo para a inovação em SI na melhoria de serviços públicos e no desenvolvimento de soluções gratuitas para a coletividade suportada por patrocinadores. 
Existem muitos estudos sobre como inovar e quais os resultados que as empresas podem colher por meio da inovação (BESSANT; TIDD, 2015). A maioria destes estudos analisa a inovação em grandes empresas, em arranjos produtivos e em setores específicos e estratégicos da economia. Estudos sobre a inovação tecnológica em pequenas e médias empresas já constituídas, em empresas nascentes, e em startups ${ }^{1}$ são em menor número. Muitos aspectos envolvendo os modelos de apoio a inovação, as oportunidades de parceria com universidades ou institutos de ciência e tecnologia (ICT), e a consolidação mercadológica deste perfil de empresa ainda precisam ser esclarecidos (SARAIVA, 2013) (BUENO; TORKOMIAN, 2011).

No lado acadêmico, o surgimento dos Núcleos de Inovação Tecnológica (NIT) torna institucionalizado o empenho das universidades em prol da inovação, criando canais que permitam apoiar seus pesquisadores empenhados em inovar. A presença dos NITs nas universidades abre novas possibilidades na relação universidade-empresa ajudando a superar resistências históricas de ambos os lados.

Avaliar os projetos apoiados, por meio de diferentes tipos de programas de apoio e de subvenção a inovação tecnológica, é fundamental para compreender: o perfil dos seus atores; os temas dos desafios propostos; a eficácia do modelo de apoio adotado; os avanços na formação de empreendedores e de empresas; o retorno econômico e social obtido.

Esta pesquisa é uma contribuição para o estudo da inovação tecnológica em pequenas empresas, pois analisa os projetos de SI que receberam apoio da FAPESP por meio do programa "Pesquisa Inovativa em Pequenas Empresas" (PIPE) no período 2010-2015. O PIPE é um programa criado pela FAPESP em 1997 para apoiar a pesquisa em ciência e tecnologia, o desenvolvimento empresarial, e aumentar a competitividade das pequenas e médias empresas. Até 2015 foram financiados cerca de 1.400 projetos, em um total aproximado de $\mathrm{R} \$ 180$ milhões de recurso aplicados (MARQUES; PIERRO, 2014). Parte destes projetos se relacionam com desenvolvimento de software e tecnologias que envolvem conhecimento computacional.

Nos projetos selecionados para esta pesquisa são analisados: - os temas que são objeto da inovação; - os beneficiários das inovações; - o perfil do pesquisador responsável e de pesquisadores assistentes para esclarecer: em que momento após a graduação participam do PIPE; qual a titulação no momento de sua participação no PIPE; por meio de que cursos de graduação e pós-graduação se formaram; quais são as instituições formadoras destes agentes da inovação.

A justificativa para este estudo é que as iniciativas de apoio a inovação tecnológica às pequenas empresas e startups no Brasil carecem de maior investigação. Ampliar as

\footnotetext{
${ }^{1}$ Exitem diferentes concepções sobre o que é uma startup, diferenciando este tipo de empresa de outras empresas nascentes. Com a explosão de novas empresas para explorar as oportunidades que a internet oferecia (a partir de meados dos anos 1990) startup ganhou o sentido de um grupo de pessoas trabalhando com uma ideia diferente com potencial de fazer dinheiro. Nesta perspectiva uma startup é uma empresa com custos de manutenção muito baixos, mas que consegue crescer rapidamente e gerar lucros cada vez maiores. Para especialistas e investidores, uma startup é um grupo de pessoas à procura de um modelo de negócios repetível e escalável, trabalhando em condições de extrema incerteza (GITAHY, 2010).
} 
análises sobre estas iniciativas, em especial para a inovação em SI, se mostra importante para compreender como os programas de apoio e subvenção à inovação funcionam, qual o perfil dos executores dos projetos apoiados, e em que medida estas iniciativas são fundamentais para o desenvolvimento destas empresas. $\mathrm{O}$ conhecimento gerado por meio deste tipo de pesquisa pode contribuir para a melhor compreensão sobre os programas de apoio a inovação tecnológica, esclarecendo os resultados obtidos nestas iniciativas e como aperfeiçoar e diversificar estes programas. Construir modelos de apoio a inovação tecnológica que contribuam para o desenvolvimento econômico e social do país é uma tarefa inadiável.

Além da Seção de Introdução, o artigo apresenta a seguinte estrutura: a Seção 2 aborda as iniciativas de apoio à inovação tecnológica no Brasil; a Seção 3 aborda as iniciativas de inovação em SI; a Seção 4 descreve a metodologia; na Seção 5 estão os resultados e as discussões. As considerações finais concluem o artigo.

\section{Iniciativas de apoio a inovação tecnológica}

A inovação tecnológica entrou apenas recentemente na agenda dos principais atores interessados: governo, empresas, universidades, empreendedores, investidores. A data de início das iniciativas nesta área é uma indicação segura da novidade que é o tema da inovação tecnológica para seus diferentes atores. A Confederação Nacional da Indústria (CNI) formaliza em 2009, por meio do documento "Inovação: A construção do futuro", a convicção dos industriais brasileiros que a inovação é prioritária para a indústria e que a ênfase na inovação exige a sinergia entre o governo e o setor privado. Entre diferentes pontos salientados neste documento, que ficou conhecido como "Manifesto pela Inovação", destacamos:

- "Nosso desempenho é muito inferior ao das economias desenvolvidas. Em
parte, isso é consequência da estrutura industrial do país. Mas sua causa
maior é nosso pequeno esforço em inovação. Ou conseguimos superar esse
descompasso, ou corremos o risco de agravar o nosso atraso"
- "Inovação é uma atividade coletiva, em que a empresa é o ator principal,
mas que depende de boa infraestrutura, sólidas instituições de pesquisa e
boas universidades. Temos feito progresso na pesquisa acadêmica, mas
nossos centros de excelência ainda são poucos. E precisamos fortalecer a
relação universidade-empresa. Nosso maior problema nessa frente continua
a ser a baixa qualidade da educação. Poucos jovens chegam à universidade-
e os que chegam nem sempre têm a formação adequada. O perfil dos
egressos não anima. As deficiências nacionais em engenharia e ciências são
inquietantes"

Observando certa ordem cronológica nas iniciativas efetivas em prol da inovação tecnológica no Brasil, tem-se dois momentos, anterior e posterior a Lei de Inovação (Lei n.10.973, 2004 e Decreto n.5.563, 2005) $)^{2}$. A Lei da Inovação busca estimular: a criação de um ambiente propício a parcerias entre as universidades, institutos tecnológicos e

\footnotetext{
${ }^{2}$ No portal do Ministério da Ciência, Tecnologia e Inovação (MCTI) existe uma área com os documentos que compõem o marco legal sobre inovação no âmbito nacional e estadual. Link: http://www.mct.gov.br/index.php/content/view/8477.html. Acesso em junho de 2016.
} 
empresas; a participação de institutos de ciência e tecnologia no processo de inovação; a inovação nas empresas; o inventor independente.

Uma forma de acompanhar o impacto da Lei de Inovação nas ICTs é acompanhar ano a ano os relatórios "Política de propriedade intelectual das instituições científicas e tecnológicas do Brasil". A Lei determina que as ICTs devem enviar anualmente ao MCTI, por meio do Formulário para Informações sobre a Política de Propriedade Intelectual das Instituições Científicas e Tecnológicas do Brasil (FORMICT), informações sobre: atividades desenvolvidas nos NITs; sua política de propriedade intelectual; criações desenvolvidas; proteções requeridas e concedidas; contratos de licenciamento ou transferência de tecnologia firmados. Nestes relatórios é possível obter informações sobre as ICTs: se a natureza é pública (federal, estadual ou municipal) ou privada; qual o estágio de implementação do NIT (implementado, em implementação, não implementado); as atividades desenvolvidas no NIT; Propriedade Intelectual (requerida e concedida); contratos de tecnologia e os rendimentos obtidos por meio destes contratos. Por meio destes dados é possível ter um indicativo da evolução das ICTs no empenho inovativo.

Para uma rápida visão ao longo do tempo, seleciona-se os dados das ICTs que constam nos relatórios dos anos 2006, 2010 e 2014 ${ }^{3}$. Os dados indicam um rápido crescimento no número de ICTs respondendo o FORMICT: de 43 em 2006 para 264 em 2014. Verifica-se no país, neste período, a predominância de instituições federais e um recente crescimento de instituições de natureza privada (em 2014 estas instituições representam $26,5 \%$ da amostra, superando numericamente as instituições estaduais).

Outro dado do Relatório FORMICT que auxilia na compreensão do empenho inovativo das ICTs é o número de proteções requeridas e proteções concedidas. Analisando os dados dos relatórios dos anos 2010 e 2014 constata-se o crescimento do número de proteções solicitadas e concedidas. As proteções requeridas cresceram de 1078 para 2163 (aumento de 100,6\%) e as proteções concedidas aumentaram de 169 para 350 (aumento de 107,1\%).

A proteção para programas de computador assume uma importante dimensão neste processo de proteção do empenho inovativo das ICTs. Observa-se um grande crescimento de 2010 para 2014, as proteções requeridas passaram de 91 para 444 (aumento de 387,9\%) e as proteções concedidas passaram de 42 para 169 (aumento de $302,3 \%$ ). Quando as proteções para programas de computador são analisadas comparativamente ao conjunto das proteções pode-se constatar a sua importância. Em 2010 os programas de computador representavam 8,4\% do total das proteções requeridas e $24,8 \%$ do total das proteções concedidas. Em 2014 os programas de computador representavam $20,5 \%$ do total das proteções requeridas e $48,3 \%$ do total das proteções concedidas. Cabe lembrar que no caso específico da criação de programas de computador a proteção, na legislação brasileira, se dá por meio do direito autoral e não

\footnotetext{
${ }^{3}$ Disponíveis em:

2006: http://www.mct.gov.br/upd blob/0024/24855.pdf;

2010: http://www.mct.gov.br/upd blob/0217/217319.pdf;

2014: http://www.mct.gov.br/upd_blob/0237/237661.pdf

Acesso: junho 2016.

CARLI, E. B.

Apoio à inovação em Sistemas de Informação: análise de projetos do PIPE - FAPESP (2010-2015)

isys | Revista Brasileira de Sistemas de Informação, Rio de Janeiro, vol. 9, No. 3, pp. 26-55, 2016
} 
por meio de patente: Lei de Software-Lei 9609/98 e Decreto 2556/98 (RODRIGUES; BERBERT; TEIXEIRA, 2013).

No caso do empenho inovativo em programas de computador, é necessária uma investigação mais ampla para esclarecer porque eles alcançaram um alto percentual entre as proteções concedidas: o preparo intelectual e científico dos recursos humanos nesta área aliado ao empenho em inovar é maior do que em outras áreas?; conceber e desenvolver um programa de computador exige menos recursos do que outras áreas?; a demanda crescente e diversificada por programas de computador na sociedade do conhecimento explicaria este crescimento?; criar um programa de computador é menos complexo do que inovar em outras áreas?; a proteção por direito autoral é mais célere que a proteção por patente? Mesmo diante destes questionamentos é fato que a criação de programas de computador cresceu, o que indica uma maior maturidade e senso de oportunidade dos desenvolvedores.

O empenho em inovar pode ser melhor compreendido quando acompanhamos o surgimento dos NITs nas universidades. A partir dos NITs, surgem as Agências de Inovação que desempenham outras funções além daquelas desempenhadas pelo NIT, desenvolvendo iniciativas relacionadas a empreendedorismo e a capacitação e promoção do ambiente de negócios relacionados à inovação tecnológica. Nas universidades paulistas temos a seguinte cronologia: "Agência de Inovação da Unicamp - Inova Unicamp" (UNICAMP, 2004); "Agência USP de Inovação" (USP, 2005); "Agência Unesp de Inovação da Universidade Estadual Paulista - AUIN" (UNESP, 2007); "Agência de Inovação da UFSCar" (UFSCar, 2008); InovaUFABC (UFABC, 2010).

Os NITs e as Agências de Inovação representam o reconhecimento do importante papel que as universidades podem desempenhar na inovação e, por outro lado, a necessidade de ter canais institucionais que promovam e suportem as iniciativas em prol da inovação. No entanto, são iniciativas recentes que ainda estão em fase de estruturação e consolidação. Os estudos indicam que é preciso um maior amadurecimento dos programas de apoio à inovação e de sua gestão nas universidades paulistas (BUENO; MACHADO, 2011) (DIAS; PORTO, 2014).

Embora recentes, estas diferentes iniciativas em prol da inovação já apresentam um conjunto de projetos e de ações concluídas, o que permite empreender a análise dos resultados obtidos com objetivo de avaliar em que medida cada uma delas alcançou os resultados esperados e que aprendizado se pode obter de sua execução (MENEZES; TEIXEIRA, 2013) (BUENO; TORKOMIAN, 2011).

\section{A inovação em sistemas de informação}

Embora um programa de computador e um software sejam tomados com frequência como sinônimos, o programa de computador é um código em uma linguagem de programação, enquanto o software é o conjunto que abarca: o programa de computador; a metodologia de operação; a documentação (que permite conhecer e explorar todas as suas possibilidades); os aspectos relacionados a licença de uso, segurança, atualização e 
o suporte ao usuário. Assim o software é um produto completo e não apenas a programação lógica que contém as instruções definindo as operações que o computador deve realizar. Para efeito desta análise, um SI é um software que busca oferecer uma solução de fácil utilização, com suporte e atualização capaz de produzir os resultados que o usuário final deseja. Isto inclui não apenas o desenvolvimento do SI em si, mas compreender o comportamento das pessoas, os melhores modelos de negócio, em captar necessidades ainda não atendidas ou atendidas de forma insatisfatória. Colocado nestes termos, criar um software parece uma tarefa cuja execução pode ser trabalhosa, mas cujo produto final é viável. O desafio consiste em criar SI que permita as pessoas "fazer mais fazendo menos" ${ }^{\prime 4}$ (DERTOUZOS, 2002).

Conhecer alguns exemplos brasileiros de inovação em SI pode auxiliar a refletir em que medida este desafio está sendo enfrentando. Entre inúmeros exemplos que auxiliam a delinear o empenho inovativo em SI nas últimas décadas, pode-se citar ${ }^{5}$ : CI\&T (1995); Estante Virtual (2004); GeeKie (2011); Easy Taxi (2012); Playax (2014).

Existem outros exemplos, com suas histórias e conquistas. Mas, além de exemplos pontuais, pode-se refletir sobre o ecossistema que anima a inovação em SI. Uma parte fundamental deste ecossistema é a formação em empreendedorismo que alunos de graduação e pós-graduação podem receber como parte de sua formação profissional. A maioria das universidades no Brasil começou a dedicar atenção a formação empreendedora muito recentemente oferecendo oficinas, palestras, e em uma minoria observa-se a oferta de uma disciplina ou um conjunto de disciplinas especificas para formar jovens inovadores e empreendedores.

Em recente reflexão intitulada "A inovação tecnológica e a educação para o empreendedorismo", Plonski e Carrer (2009) descrevem a evolução de diferentes modelos de universidade desde sua origem até o modelo recente da universidade empreendedora e questionam se é possível obter resultados práticos da inovação sem investir na formação empreendedora. Como parte da resposta a esta questão, os autores destacam a importância da participação da universidade em incubadoras, aceleradoras de negócios, parques tecnológicos e diferentes mecanismos de apoio a inovação que permitem aos alunos vivenciar o processo de empreendedorismo inovador que se desenvolve no país.

\footnotetext{
4 "Quando os sistemas de informação atingirem o status do avião a jato, bem adiante neste século, focalizaremos a utilidade acima da moda passageira, triplicaremos nossa produtividade, usaremos os computadores com tanta naturalidade, facilidade e prazer como usamos carros e geladeiras e ouviremos as vozes de centenas de milhões de pessoas - se abandonarmos esse caminho frustrante que leva à complexidade desenfreada e crescente da máquina. (...) Precisamos estabelecer uma nova meta, tão óbvia e simples quanto poderosa: a tecnologia da informação deve ajudar as pessoas a fazer mais fazendo menos. A computação centrada no homem é a abordagem que conduz a esse objetivo e que concluirá a Revolução Inacabada."

${ }^{5}$ Para saber mais: CI\&T < http://revistapesquisa.fapesp.br/2014/06/16/conquista-mundo/ >; Estante Virtual $<$ http://www.estantevirtual.com.br/imprensa $>$; GeeKie $<$ http://www.innoveedu.org/pt/geekie$\underline{\text { lab }}>$; Easy Taxi $<$ http://exame.abril.com.br/revista-exame-pme/edicoes/82/noticias/a-corrida-dos-taxis$\underline{2}>$; Playax < http://www.bv.fapesp.br/pt/auxilios/89372/plataforma-de-identificacao-automatica-demusicas-e-gestao-de-direitos-autorais/ >. Acesso: junho 2016.
} 
A tendência no próximo quarto de século é que a incubação, como gênero, se torne parte natural do processo de ensino-aprendizagem em todas as áreas - humanas, biológicas e exatas. Essas incubadoras universitárias são de espécies diversas - de empresas, de negócios, de projetos, de soluções sociais, de criações artísticas e outras tantas. O que há de comum entre elas é o foco na gestão dos processos que transformam ideias que sejam, ao mesmo tempo, qualificadas e criativas, em produtos e soluções reais, utilizados pela sociedade. (...) a incubadora, permite aos estudantes aprender a ciência e arte de combinar conhecimentos preexistentes e novos na geração de valor percebido pela sociedade, incorporado em bens e serviços. As incubadoras permitem destarte que o corpo discente vivencie integralmente, junto com seus docentes, o que se vem denominando de "triângulo do conhecimento" - que articula educação, pesquisa e inovação.

Uma clara indicação de que as universidades começam a trilhar este caminho apontado é que: - das 420 incubadoras de empresa no Brasil, cerca de $85 \%$ delas têm forte vínculo com as universidades ou institutos de pesquisa; - dos 70 parques tecnológicos no país, as universidades são parceiros-chave em grande parte deles (PLONSKI, CARRER, 2009). As incubadoras e os parques tecnológicos são iniciativas para a construção de ambientes favoráveis ao empreendedorismo inovador.

Neste aspecto, merece destaque a criação, no ano 2000, em Recife, do Porto Digital. Iniciativa do poder público para promover o desenvolvimento de um ambiente de negócios em tecnologia da informação é hoje um dos principais parques tecnológicos e ambientes de inovação do Brasil. Com atuação focada em software e serviços de Tecnologia da Informação e Comunicação (TIC) e Economia Criativa (EC), com ênfase nos segmentos de games, multimídia, cine-vídeo-animação, música, fotografia e design o Porto Digital abriga 250 empresas, organizações de fomento e órgãos de Governo e ao longo de seus 15 anos de existência gerou 7,5 mil empregos. Atualmente as empresas que ali estão faturam R\$ 1 bilhão por ano (BELLONI, 2015) (PAIVA JÚNIOR et al, 2014).

A demanda por inovação em serviços públicos também pode compor o ecossistema de inovação em SI. Em 2015 o governo do Estado de São Paulo realizou a primeira edição do Pitch Gov SP, que consiste em uma iniciativa que busca selecionar 15 startups que devem apresentar soluções inovadoras para ajudar o poder público a solucionar desafios ${ }^{6}$ da administração pública nas áreas de saúde, educação e facilidades ao cidadão. É uma solução pioneira em toda a América Latina que segue o modelo de iniciativas bem-sucedidas na Europa e Estados Unidos.

Outra iniciativa é o Desafio Brasil (http://www.openstartups.org.br/db/), um programa educacional voltado ao empreendedorismo e a inovação onde startups de jovens empreendedores competem pelo reconhecimento e visibilidade da comunidade de venture capital nacional e internacional. Em sua $10^{\mathrm{a}}$ edição, percorreu 10 cidades inovadoras pelo país oferecendo acesso a recursos que contribuíram para que ideias

\footnotetext{
${ }^{6}$ Veja os desafios propostos em: http://www.governo.sp.gov.br/pitchgovSP/Desafios\%20Pitch\%20Gov\%20SP.pdf. Acesso junho 2016. 
empreendedoras atingissem todo o seu potencial e ficassem em evidência no movimento Open Startups.

Estes são exemplos que comprovam que grande parte das inovações, no século XXI, se dará por meio de startups. Elas demonstram ser capazes de desenvolver produtos e serviços em curto prazo a custos menores, possuem equipes mais motivadas que nas grandes empresas, e conseguem rapidamente expandir ao captar recursos de investidores ou fundos de investimento ávidos por boas oportunidades de negócio (FIORAVANTI, 2016).

Deste modo, cabe reconhecer que temos um ecossistema de inovação em SI no Brasil que se amplia, se diversifica e se aperfeiçoa. Este ecossistema proporciona, não sem desafios e incertezas, novas fronteiras para todos que desejam inovar e empreender.

\section{Metodologia}

\subsection{Acesso a base de dados}

Existem diferentes experiências e programas de apoio à inovação tecnológica, nas universidades, nas fundações de amparo a pesquisa, nos parques tecnológicos, e mais recentemente em aceleradoras de empresas. Entre estes exemplos, podemos citar: Programa de Formação de Recursos Humanos em Áreas Estratégicas (RHAE) vinculado ao CNPq e MCTI, iniciado em 1987; PIPE da FAPESP, iniciado em 1997; O Parque Tecnológico Porto Digital em Recife, iniciado em 2000; Aceleratech, iniciada em 2012.

O estudo de diferentes programas de apoio a inovação em SI depende principalmente do acesso a informação sobre os projetos concluídos e em andamento, em especial quando estamos em busca de respostas sobre: o tema do projeto e sua área de aplicação, o perfil acadêmico daqueles que participam dos projetos, resultados obtidos, impacto econômico e social.

O RHAE não dispõe de uma base única de dados que reúna as informações dos projetos concluídos e em execução. Os dados dos projetos apoiados estão dispersos no site do CNPq. O nome dos pesquisadores responsáveis e o título do projeto estão em: $\mathrm{CNPq}>$ Chamadas Públicas $>$ Encerradas $>$ RHAE. Informações sobre os projetos e suas aplicações estão em: $\mathrm{CNPq}>$ Programas $>$ RHAE $>$ Arquivos. Informações sobre os bolsistas em cada um dos projetos não foram encontradas.

O PIPE apresenta uma base de dados com todos os projetos apoiados deste seu início. Nesta base, para cada projeto, é possível obter dados sobre: o pesquisador responsável e os bolsistas; vigência; termos chaves e resumo.

No site do Porto Digital é possível acessar a relação das empresas apoiadas e seu endereço eletrônico. A visita ao site das empresas permite identificar seu portfólio de produtos e serviços e assim identificar aqueles relacionados ao desenvolvimento de SI. A dificuldade, neste caso, é identificar qual o papel desempenhado pelo Porto Digital no 
desenvolvimento de um determinado o produto ou serviço inovador de uma empresa e os atores envolvidos na inovação.

A Aceleratech, uma das nove aceleradoras credenciadas pelo MCTI para o programa Start-up Brasil, mantém em seu portfólio 45 empresas aceleradas. É possível, assim como no caso do Porto Digital, acessar o site das empresas e verificar qual inovação em SI faz parte dos produtos e serviços oferecidos. Entretanto, não está claro a contribuição da Aceleratech no desenvolvimento destas inovações, nem que são os atores envolvidos em cada uma delas.

O RHAE e o PIPE são os melhores casos de estudo por apresentar propostas de apoio à inovação bem estruturadas e com grande número de projetos apoiados. O RHAE tem amplitude nacional, exige uma contrapartida financeira da empresa em $20 \%$ dos recursos destinados ao projeto, e atende desde as micros até as grandes empresas. $\mathrm{O}$ PIPE se restringe a empresas sediadas no Estado de São Paulo com até 250 funcionários e os recursos destinados aos projetos não exigem reembolso nem contrapartida.

Entre os exemplos acima citados, e outros previamente sondados, o PIPE é o que melhor atende as necessidades de acesso a dados para a realização de um estudo sobre programas de apoio a inovação para as pequenas empresas, motivo pelo qual foi escolhido para este estudo.

\subsection{A escolha de projetos de inovação em SI na base de dados do PIPE}

Utilizando a base aberta de dados da FAPESP, no link Biblioteca Virtual, selecionamos todos os projetos PIPE desde o seu início até outubro de 2015. Obtivemos 3584 itens, que incluem dados de todos os projetos e as bolsas vinculadas aos projetos.

A figura 1 exemplifica as informações contidas em um item cadastral da base de dados. Entre as informações disponíveis destacamos: título do projeto; vigência; pesquisador responsável; bolsista; assunto; e resumo.

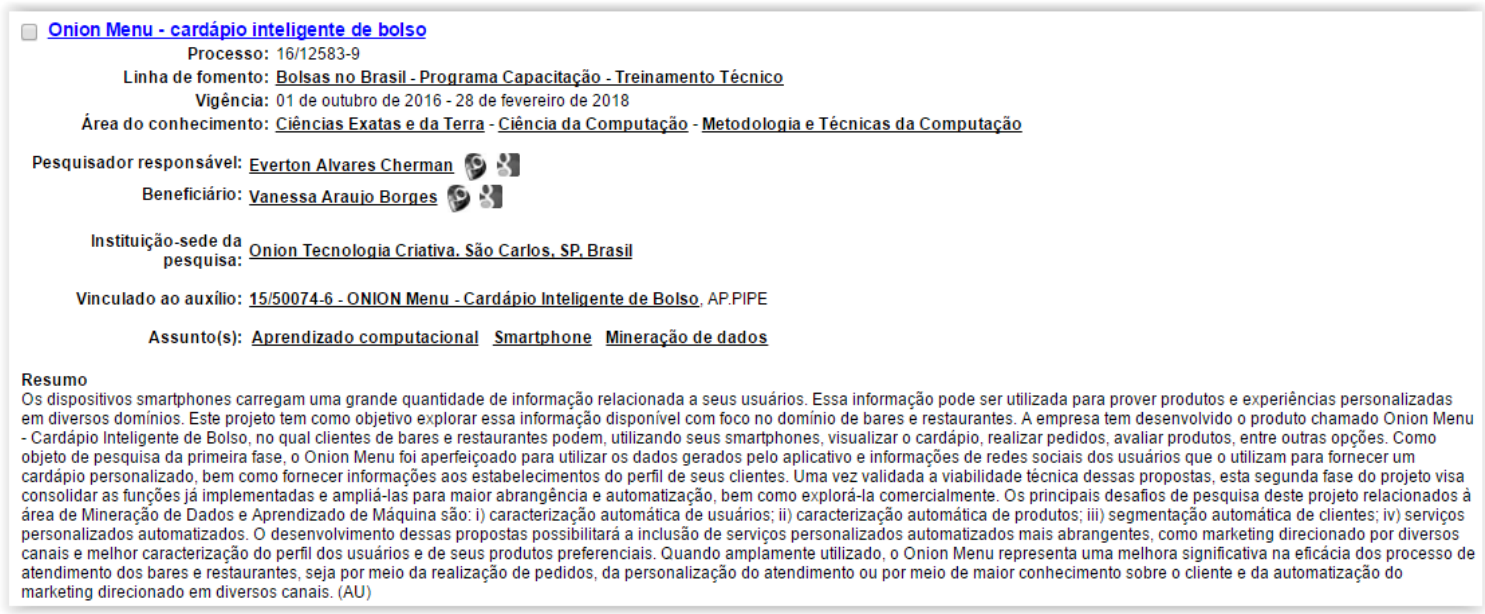

Figura 1 - Item cadastral de projeto do PIPE indicando as informações disponíveis 
Para selecionar os projetos de inovação em SI nesta base de dados foram adotados os seguintes critérios:

(a) Selecionar projetos no período 2010 a 2015. Analisar todos os projetos de inovação em SI desde o início do PIPE seria um estudo bastante amplo e incluiria projetos que já perderam parte de sua relevância e impacto. Neste estudo se faz a análise do período 2010-2015 (até $2^{\circ}$ ciclo), com objetivo de destacar os projetos mais recentes e assim os temas atuais de inovação nesta área;

(b) Selecionar projetos em que o desenvolvimento de um SI seja o objetivo central do projeto. Esta restrição é necessária pois o desenvolvimento de um SI pode exigir diferentes competências e atender a necessidades bastante específicas. Opta-se então, por não incluir na análise projetos que exigem desenvolvimento de software, mas cujo empenho maior é dedicado a: desenvolvimento de hardware; tecnologia de transmissão de dados; redes de computadores; servidores; telecomunicações. Desta forma, projetos cujo objeto da inovação é do âmbito mais específico da Ciência da Computação, da Engenharia da Computação ou da Engenharia Elétrica não são incluídos entre os projetos de inovação em SI.

\subsection{As questões deste estudo}

Com as informações disponíveis nos itens cadastrais da base de dados do PIPE é possível responder as questões: quais os temas dos projetos (área de aplicação); quem são os beneficiários da inovação (os usuários finais do SI desenvolvido); quem são os pesquisadores do projeto (responsável e bolsistas); período de realização do projeto.

A classificação da áreas de aplicação em categorias é obtida pela análise, nos arquivos cadastrais dos projeto, das informações contidas no resumo e nos termos chaves. Estas informações indicam as soluções que se espera obter e os potenciais usuários do SI, permitindo reconhecer os temas e os desafios de maior interesse para aqueles que se propõem a inovar. É importante alertar, que em um estudo exploratório, estas categorias apontam tendências, deste modo não é possível fazer generalizações.

Em complemento, a identificação dos pesquisadores do projeto, foi consultada também a base de dados da Plataforma Lattes para obter o currículo destes pesquisadores. Desta forma podemos responder as seguintes questões sobre estes pesquisadores: (i) quanto tempo após a graduação os pesquisadores participam do PIPE; (ii) qual a titulação dos pesquisadores no momento de sua participação no PIPE; (iii) qual o curso realizado na graduação, especialização, mestrado, doutorado; (iv) em qual instituição de ensino cada etapa da formação acadêmica foi realizada. Os itens (i) e (ii) podem ser respondidos pelo cruzamento entre a data de participação no PIPE e a data de conclusão da graduação, mestrado, doutorado. Os itens (iii) e (iv) podem ser respondidas pelos dados do currículo.

A resposta a estas questões auxilia no reconhecimento do perfil acadêmico daqueles que desenvolveram projetos inovadores em SI no PIPE. Esta metodologia também poderia ser aplicada nos projetos de SI do RHAE (com maior dificuldade devido a dispersão das informações) ou outros projetos inovadores de SI, desde que as informações estejam disponíveis. 


\section{Resultados e discussões}

\subsection{A seleção dos projetos em SI do PIPE}

A aplicação do primeiro critério de seleção (projetos no período 2010-2015), na base de dados do PIPE, restringiu a pesquisa para pouco mais de 900 itens com projetos em todas as áreas.

Entre estes projetos, foram selecionados 85 projetos que apresentaram algum objetivo relacionado à inovação em SI (a partir das informações contidas no título, no resumo e nos termos chaves). Após a aplicação do segundo critério foram selecionados 33 projetos para compor este estudo. Nestes 33 projetos selecionados encontramos um total de 36 pesquisadores responsáveis e 52 bolsistas (pesquisadores associados). Isto é, tem-se 88 itens cadastrais do PIPE que compõe a amostra a ser analisada.

Os resultados apresentados a seguir são obtidos das informações destes 88 itens cadastrais e dos currículos de pesquisadores disponíveis na Plataforma Lattes.

\subsection{Inovação em sistemas da informação para quem?}

Uma pergunta fundamental no início do desenvolvimento de um SI é: quem será beneficiado pelo seu uso. Para pequenas empresas reconhecer necessidades não atendidas ou atendidas de forma insatisfatória para propor produtos ou serviços inovadores que atenda às necessidades dos usuários é uma questão estratégica e vital para os negócios. Este é o motivo pelo qual identificar as áreas de aplicação e os usuários beneficiados pelos projetos propostos ajuda a reconhecer onde estão os desafios e as necessidades de inovação em SI.

A análise dos 33 projetos que compõem esta amostra conduziu a classificação dos projetos em sete categorias de aplicação: Agricultura; Ambiental; Aplicativos Web; Educação; Esportes; Medicina/Saúde; Software Corporativo.

Na categoria Aplicativos Web (21,2\%) estão SI cuja finalidade é oferecer a um grande número de usuários finais aplicativos que tornarão acessíveis a execução de determinadas tarefas. Estes aplicativos oferecem notáveis ganhos seja na abrangência de usuários finais, seja na capacidade de resolver problemas que outras formas seriam difíceis ou impossíveis de serem resolvidos. A tabela 1 indica o título dos projetos desta categoria, os termos utilizados em "assunto", e o site da empresa (quando disponível).

\section{Tabela 1. Projeto de SI na categoria Aplicativos Web}

\begin{tabular}{l} 
Aplicação da plataforma mobinet para gerenciamento de alumni em instituições de ensino superior \\
Assunto: Aplicação Web 2.0; Arquitetura orientada a serviços; Comunidade virtual; Ensino superior; \\
Instituições acadêmicas; Internet; Java; Plataforma (computação); Rede de comunicação; Redes \\
sociais; Tecnologia da comunicação; Tecnologia da informação; Telefonia móvel. \\
\hline Desenvolvimento de software site para administração de ativos e gestão institucional \\
Assunto: Administração de empresas; Desenvolvimento de software; Manutenção de software; \\
Tecnologia da informação; Web sites. \\
\hline Onion: cardápio inteligente de bolso \\
Assunto: Aplicativos móveis; Aprendizado computacional; Bares; Cardápios; Dispositivos móveis; \\
Inteligência artificial; Marketing digital; Mineração de dados; Perfil de consumo; Redes sociais; \\
Restaurantes; Smartphone. http://www.onionapp.com.br/
\end{tabular}


Semantic sensys: solução semântica de inteligência competitiva para comércio eletrônico

Assunto: Comércio eletrônico; Inteligência competitiva; Ontologia (ciência da computação); Semântica; Sistemas de informação; Web crawler; Web semântica.

Sistema inteligente de estacionamento utilizando rede de sensores sem fio

Assunto: Dispositivos móveis; Estacionamentos; Inovação; Internet das coisas; Monitoramento; Redes de monitoramento; Sensores remotos; Wireless.

Uma aplicação móvel para obtenção de informações atualizadas de transporte público a partir do conhecimento coletivo

Assunto: Análise de dados; Aplicativos móveis; Bases de conhecimento; Crowdsourcing; Desenvolvimento de software; Dispositivos móveis; Inteligência coletiva; Mobilidade urbana; Plataforma (computação); Redes de monitoramento; Transporte público.

http://www.scipopulis.com/

Busca facetada de patentes com adaptação sob demanda de modelagem de tópico

Assunto: Aprendizado computacional; Informação; Patentes; Processamento de linguagem natural; Prospecção tecnológica; Recuperação da informação; Visualização de informação.

$\underline{\text { http://www.elaboraconsultoria.com.br/ }}$

Na categoria Medicina/Saúde (18,1\%) estão SI cuja finalidade é: (i) prover o médico/a equipe médica do tipo de informação necessária e no formato mais adequado para o bom desempenho de suas funções; (ii) prover o sistema de saúde de ferramentas que auxilie na gestão de plantões médicos; (iii) prover o sistema de saúde de um sistema de gestão de medicamentos. A tabela 2 indica o título dos projetos desta categoria, os termos utilizados em "assunto", e o site da empresa (quando disponível).

\section{Tabela 2. Projeto de SI na categoria Medicina/Saúde}

Arcamed: um arcabouço para construção de sistemas de apoio a diagnósticos médicos

Assunto: Computação móvel; Computação ubíqua; Diagnóstico clínico; Hipermídia; Informática médica; Multimídia; Recuperação da informação; Software.

http://www.innolution.com.br/

Desenvolvimento de um aplicativo de acesso móvel ao sistema de regulação médica de urgências e emergências

Assunto: Computação móvel; Desenvolvimento de software; Desenvolvimento de tecnologia; Dispositivos móveis; Informática médica; Processamento de imagens; Serviços médicos de emergência.

http://kidopi.com.br/

Desenvolvimento de base inovadora de informação sobre medicamentos integrada aos sistemas público e privado de saúde: parceria estratégica entre a Faculdade de Ciências Farmacêuticas da Universidade de São Paulo e a Sollis - Soluções integradas à saúde Ltda para promoção do uso racional de medicamentos

Assunto: Acesso à informação; Assistência farmacêutica; Bases de dados; Sistema Único de Saúde; Uso de medicamentos.

http://www.sollisinovacao.com.br/

Plataforma mobile de organização de plantões médicos - Medtime

Assunto: Administração hospitalar; Aplicativos móveis; Banco de dados; Medicina; Plantão médico; Smartphone; Tablet (dispositivos móveis); Tecnologia da informação; Tecnologia sem fio.

Separador automatizado de medicamentos para farmácias hospitalares

Assunto: Automação industrial; Bioengenharia; Farmácia hospitalar; Medicamentos; Prescrição eletrônica; Prescrições de medicamentos; Robótica.

http://www.dankia.com.br/

Software de apoio a equipe multidisciplinar no planejamento terapêutico de tumores cerebrais

Assunto: Mineração de dados; Neoplasias; Ontologia; Softwares.

Na categoria Agricultura (18,1\%) estão SI cuja finalidade é coletar informações e tratar estas informações para oferecer sistemas que permita tomar decisão mais 
qualificadas e que maximizem resultados. A tabela 3 indica o título dos projetos desta categoria, os termos utilizados em "assunto", e o site da empresa (quando disponível).

\section{Tabela 3. Projeto de SI na categoria Agricultura}

Análise de viabilidade técnico-científica de um sistema de visão computacional para a classificação de
mudas de flores e plantas ornamentais
Assunto: Aprendizado computacional; Aprendizado de máquina; Botânica (classificação); Flores;
Inovação; Inteligência artificial; Mudas (plantas); Plantas ornamentais; Violeta; Visão computacional.
http://www.mvisia.com.br
Desenvolvimento de um aplicativo mobile para acesso a informações sobre o mercado florestal
brasileiro
Assunto: Acesso à informação; Aplicativos móveis; Brasil; Florestas; Gestão da informação;
Smartphone; Tablet (dispositivos móveis)
http://www.atriumforest.com/
Maxibi, desenvolvimento de um sistema de inteligência de negócio para o setor bioenergético com
ferramentas de mineração de dados e apoio a tomada de decisão
Assunto: Agronegócio; Banco de dados; Bioenergética; Data warehouse; Desenvolvimento de
software; Mineração de dados; Tomada de decisão.
Proposta de um método de gestão logístico aplicado ao transporte de trabalhadores rurais em frente
agrícolas
Assunto: Hardware; Logística; Sistema de posicionamento global (GPS); Softwares; Transporte rural.
http://www.logtrac.com.br/
Sistema de apoio a tomada de decisão para rotação de culturas em sistema plantio direto
Assunto: Banco de dados; Pesquisa operacional; Plantio direto; Rotação de culturas; Sistemas de apoio
à decisão.
Sonar: sistema de inteligência competitiva e prospecção de negócios para organizações agroindustriais
Assunto: Agronegócio; Coleta de dados; Difusão da informação; Estratégia organizacional; Gestão da
informação; Indústria agrícola; Inteligência artificial; Inteligência competitiva; Semiótica; Software;
Tecnologia da informação.

$\mathrm{Na}$ categoria Educação (12,1\%) estão SI cuja finalidade é prover educadores e educandos de novas ferramentas que promovam o ensino e o aprendizado de forma massiva (escalabilidade) e qualificada (com ganhos em desempenho e qualidade na educação). A tabela 4 indica o título dos projetos desta categoria, os termos utilizados em "assunto", e o site da empresa (quando disponível).

\section{Tabela 4. Projeto de SI na categoria Educação}

\begin{tabular}{|c|}
\hline $\begin{array}{l}\text { 3Dclass+: plataforma virtual gamificada para ensino e avaliação de desempenho de jovens a distância } \\
\text { Assunto: Educação; Educação a distância; Jovens; Ludificação; Plataforma (computação); Plataformas } \\
\text { de ensino e aprendizagem; Tecnologia educacional. } \\
\text { http://www.opusphere.com/ }\end{array}$ \\
\hline Biomabilidade 3d: imagens interativas para dispositivos móveis (tablets e smartphones) sobre os \\
\hline biomas brasileiros \\
\hline $\begin{array}{l}\text { Assunto: Computador no ensino; Dispositivos móveis; Ecossistemas; Imagem 3D; Processamento de } \\
\text { imagens; Smartphone; Tablet (dispositivos móveis). }\end{array}$ \\
\hline Cynorms: uma plataforma virtual em 3d para auxílio ao aprendizado \\
\hline $\begin{array}{l}\text { Assunto: Educação a distância; Imagem tridimensional; Interatividade; Plataformas de ensino e } \\
\text { aprendizagem; Realidade virtual; Tecnologia educacional. }\end{array}$ \\
\hline Sistema de suporte ao ensino de empreendedorismo \\
\hline
\end{tabular}

Na categoria Software Corporativo (15,1\%) estão SI cuja finalidade é prover uma empresa de ferramentas que permita que elas alcancem com êxito a missão e os 
propósitos a que se destinam. Não são, portanto, sistemas utilizados por um grande número de usuários finais, sendo restrito daquele contexto corporativo. A tabela 5 indica o título dos projetos desta categoria, os termos utilizados em "assunto", e o site da empresa (quando disponível).

\section{Tabela 5. Projeto de SI na categoria Software Corporativo}

\begin{tabular}{|c|}
\hline $\begin{array}{l}\text { Agenda: sistema integrado de gestão operacional de empresas aéreas } \\
\text { Assunto: Aviação; Desenvolvimento de software; Empresas de transportes; Gestão por processos; } \\
\text { Operação de aeronaves; Planejamento estratégico; Redução de custos; Sistemas de apoio à decisão; } \\
\text { Softwares; Transporte aéreo; Voo (engenharia de aeronaves). }\end{array}$ \\
\hline $\begin{array}{l}\text { Análise do potencial de ganho de produtividade na gestão de suprimentos odontológicos mediante } \\
\text { adoção de solução baseada em plataforma colaborativa }\end{array}$ \\
\hline $\begin{array}{l}\text { Assunto: Administração de consultório; Equipamento odontológico; Odontologia; Softwares; } \\
\text { Suprimentos. } \\
\text { http://www.sw2it.com/ }\end{array}$ \\
\hline Sistema de gestão de big bags laváveis, baseado em tecnologia RFDI \\
\hline Assunto: Coleta de dados; Desenvolvimento de software; Radiofrequência; Segurança alimentar. \\
\hline $\begin{array}{l}\text { Desenvolvimento do sistema integrado de previsão e segurança (SIPS): modelo de previsão para } \\
\text { monitoramento de terminais portuários costeiros }\end{array}$ \\
\hline $\begin{array}{l}\text { Assunto: Amarração; Modelos matemáticos; Navios; Ondas (oceanografia); Portos marítimos; Redes } \\
\text { de monitoramento; Segurança portuária. } \\
\text { http://www.siabr.com/ }\end{array}$ \\
\hline Plataforma de identificação automática de músicas e gestão de direitos autorais \\
\hline
\end{tabular}

$\mathrm{Na}$ categoria Ambiental (9,0\%) estão SI cuja finalidade é tratar informações complexas em um formato mais acessível aos usuários finais facilitando e ampliando o acesso a ferramentas essenciais no tratamento das questões ambientais. A tabela 6 indica o título dos projetos desta categoria, os termos utilizados em "assunto", e o site da empresa (quando disponível).

\section{Tabela 6. Projeto de SI na categoria Ambiental}

Estudo de criação de um software para desenvolvimento de documento de concepção de projeto (DCP)
pelo uso da metodologia de projeto de mecanismo de desenvolvimento limpo (MDL)
Assunto: Créditos de carbono; Desenvolvimento de software; Desenvolvimento sustentável; Gases do
efeito estufa; Gestão ambiental; Meio ambiente.
Simplificar a complexidade espacializando dados para gestão socioambiental em áreas costeiras: teste
de produto
Assunto: Geoprocessamento; Geotecnologias; Gerenciamento costeiro; Gestão ambiental; Impactos
ambientais; Sistema de informação geográfica (SIG).
Desenvolvimento de um sistema de informação para gerenciamento de logística reversa, baseado em
$\underline{\text { sistemas de informação geográficos e algoritmos de otimização utilizando colônia de formigas (Ant }}$
Colony)
Assunto: Sistema de informação geográfica (SIG); Sustentabilidade; Tecnologia da informação.
http://www.verdaz.com.br/

$\mathrm{Na}$ categoria Esportes (6,0\%) estão SI cuja finalidade é prover treinadores e atletas de novas ferramentas móveis (tablet) que promovam melhores formas de análise e tomada de decisão em treinamentos e em competições. A tabela 7 indica o título dos projetos desta categoria, os termos utilizados em "assunto", e o site da empresa (quando disponível). 


\section{Tabela 7. Projeto de SI na categoria Esportes}

Pesquisa e desenvolvimento de uma aplicação de apoio a esportes coletivos utilizando tablet pc.

Assunto: Administração esportiva; Análise estatística de dados; Desenvolvimento de software; Esportes; Esportes por equipe; Estatística; Metodologia e técnicas de computação; Planejamento tático; Sistemas de computação; Sistemas de informação; Tablet (dispositivos móveis). http://www.clansoft.com.br

Pesquisa e desenvolvimento de uma aplicação de apoio a esportes coletivos utilizando interfaces pen based

Assunto: Administração esportiva; Análise estatística de dados; Desenvolvimento de software; Esportes; Esportes por equipe; Estatística; Metodologia e técnicas de computação; Planejamento tático; Sistemas de computação; Sistemas de informação; Tablet (dispositivos móveis).

http://www.clansoft.com.br

Para além da classificação dos projetos de SI em categorias, que refletem sua aplicação e usuários beneficiados, as informações contida nas fichas cadastrais dos projetos, apontam para: uma grande ênfase em SI para uso em dispositivos eletrônicos móveis (smartphones e tablets); a importância do SI como ferramentas de gestão, de apoio a decisão em diferentes setores (educacional, agrícola, saúde, ambiental, e principalmente no ambiente corporativo); ao lado de aspectos básicos como a coleta de dados, banco de dados e recuperação de informação, encontramos nos projetos o uso de estratégias mais elaboradas utilizadas para dar sentido aos dados, tais como: semântica, ontologia, inteligência artificial, mineração de dados.

Os projetos analisados neste estudo representam uma pequena parcela de todas as iniciativas relacionadas ao desenvolvimento de SI inovadores espalhados pelo Brasil. Para ter um retrato mais fiel das áreas e dos usuários que estão na mira dos inovadores seria necessário replicar estudos semelhantes em outras iniciativas de inovação em SI por todo o Brasil, tais como: TECNOPUC (PUC-RS), INCAMP (UNICAMP-SP), Minas Digital (Governo de Minas Gerais), entre outras.

\subsection{Quanto tempo após a graduação os pesquisadores participam do PIPE?}

Em relação aos pesquisadores responsáveis pelo projeto os resultados indicam que a experiência profissional ou a experiência com a pesquisa científica adquirida após a graduação ao longo de muitos anos se manifesta como um requisito importante para a participação em um projeto do PIPE. O gráfico 1 indica a distribuição dos pesquisadores responsáveis em relação ao tempo que se passa desde a conclusão da graduação até o momento em que estão participando do PIPE.

\section{Gráfico 1: Pesquisadores Responsáveis: Anos após a graduação até o PIPE}

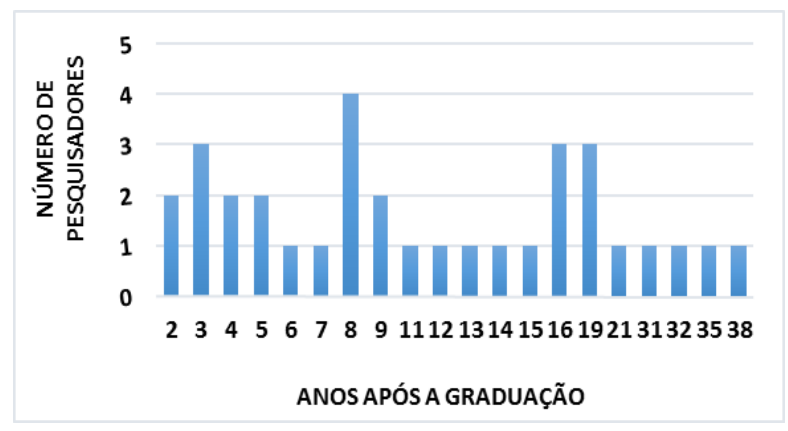

Fonte: Elaboração própria 
Embora o perfil com maior experiência seja determinante no período estudado (2010-2015), este é um cenário que pode se modificar. Constatou-se que $21,2 \%$ dos pesquisadores responsáveis ${ }^{7}$ alcançaram esta posição de liderança no PIPE em um tempo que não ultrapassa quatro anos após a conclusão da graduação. Monitorar este indicador ao longo do tempo pode ser importante para se certificar se o movimento para promover a cultura da inovação tecnológica e do empreendedorismo nas universidades e na sociedade está de fato motivando os jovens talentos a participar do PIPE ou de outras iniciativas de apoio à inovação em SI.

Em relação aos pesquisadores assistentes do projeto, os resultados apresentam uma distribuição diferente dos resultados obtidos entre os pesquisadores responsáveis. É notável uma expressiva presença de pesquisadores assistentes participando do PIPE poucos anos após o término da graduação. Tem-se 24 pesquisadores assistentes $(58 \%)^{8}$ participando em projetos do PIPE em um tempo que não ultrapassa cinco anos após a conclusão da graduação. A presença de pesquisadores assistentes mais experientes também se revela fundamental nos projetos do PIPE. Encontrou-se 14 deles (34\%) entre aqueles que já concluíram a graduação a mais de dez anos. $\mathrm{O}$ gráfico 2 indica a distribuição dos pesquisadores assistentes em relação ao tempo que se passa desde a conclusão da graduação até o momento em que estão participando do PIPE.

\section{Gráfico 2: Pesquisadores Assistentes: Anos após a graduação até o PIPE}

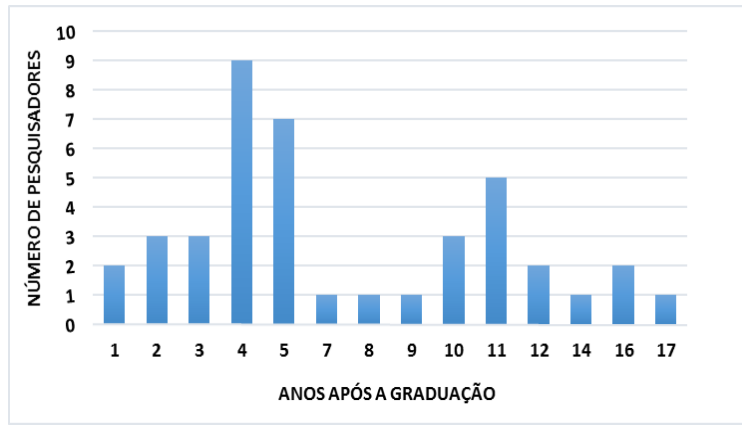

Fonte: Elaboração própria

Estes dados precisam ser considerados como uma análise de primeira ordem. Quando se examina detidamente cada projeto em sua especificidade é possível constatar que existem projetos: sem nenhum pesquisador assistente; com três pesquisadores assistentes ainda na graduação; com três pesquisadores assistentes doutores.

Este tipo de aprofundamento, analisando o papel dos pesquisadores assistentes, é feito verificando a trajetória acadêmica e profissional destes pesquisadores e confrontando com o papel que desempenham no projeto. Esta análise é apresentada no item 5.4.

\footnotetext{
${ }^{7}$ Embora o universo de pesquisadores responsáveis seja de 36 pessoas, não foi possível obter informação sobre a graduação para 3 pesquisadores. Deste modo temos uma relação de 7 pesquisadores com até 4 anos após a graduação em 33 pesquisadores responsáveis.

${ }^{8}$ Embora o universo de pesquisadores assistentes seja de 52 pessoas, não foi possível obter informação sobre a graduação para 8 pessoas e 3 pessoas ainda cursam a graduação. Deste modo temos uma relação de $24 \mathrm{em} 41$.
} 


\subsection{Qual a titulação dos pesquisadores no momento de sua participação no PIPE?}

Em relação aos pesquisadores responsáveis pelo projeto os resultados indicam uma predominância daqueles com titulação maior que a graduação: $26,4 \%$ são mestres e $26,4 \%$ são doutores. Incluindo os que estão cursando o mestrado e doutorado junto com aqueles que já obtiveram o mestrado e o doutorado tem-se $64,7 \%$ dos pesquisadores responsáveis. Estes resultados apontam para o fato de que a titulação do pesquisador responsável é um fator de grande importância, pois é uma forma de mensurar o grau de conhecimento que é necessário para enfrentar com sucesso os desafios do projeto proposto. Por outro lado, ser portador de diploma de graduação ou possuir uma especialização como maior titulação acadêmica não é uma barreira para obter recursos do PIPE. Pesquisadores graduados ou com especialização representam 35,2\% dos pesquisadores responsáveis. Pode-se dizer que está é uma característica notável do PIPE, a de aceitar para a função de pesquisador responsável pessoas que comprovem ter qualificação técnica e liderança compatível com a proposta do projeto apresentado sem impor como barreira a exigência de uma titulação acadêmica mínima (mestrado, doutorado, pós-doutorado) para esta função.

Como já salientado anteriormente, estes dados precisam ser considerados como uma análise de primeira ordem. Quando se examina detidamente cada projeto em sua especificidade é possível constatar que existem projetos em que: o pesquisador responsável (com graduação) lidera pesquisadores associados que possuem mestrado ou doutorado; o pesquisador responsável e os associados são todos doutores; o pesquisador responsável atua sozinho, sem nenhum pesquisador associado.

É importante não perder de vista que aqui está sendo analisando o PIPE por meio de um recorte bastante específico: projetos de desenvolvimento de SI. Neste caso está-se diante de desafios multidisciplinares de inovação que precisam reunir conhecimentos em computação com a correta interpretação das necessidades daqueles que se beneficiarão do SI desenvolvido.

Projetos de outras áreas contempladas pelo PIPE como, Química, Farmacologia, Energia, entre outras, podem exigir um perfil mais específico e menos multidisciplinar entre os pesquisadores que participam do projeto.

Quando se olha para um SI que se destina ao setor agrícola, tem-se pesquisadores formados em engenharia agronômica e engenharia florestal. Em um SI destinado a solucionar demandas de gestão de áreas costeira e portos tem-se pesquisadores formados em oceanografia. Em um SI destinado a gerenciar o direito autoral na execução de músicas em diferentes mídias tem-se um especialista em direito autoral trabalhando junto com um especialista em computação. Em projetos com dispositivos móveis, onde atender questões de interação humano-computador é fundamental para projetar a melhor interface, tem-se uma maior concentração de especialistas de áreas como ciências da computação, sistemas de informação e engenharia da computação. Deste modo, a amostra que compõe esta pesquisa aponta para uma diversidade de projetos que resultam em diferentes arranjos quanto a titulação. $\mathrm{O}$ gráfico 3 indica a titulação dos pesquisadores responsáveis no momento em que estão participando do PIPE. 


\section{Gráfico 3: Titulação do pesquisador responsável no momento do PIPE}

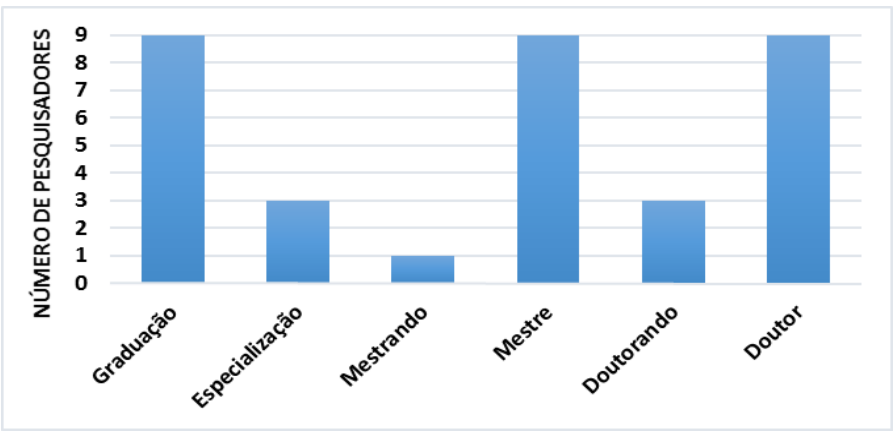

Fonte: Elaboração própria

Em relação aos pesquisadores associados ao projeto, os resultados apresentam uma distribuição diferente dos resultados obtidos entre os pesquisadores responsáveis. A predominância é dos graduados, eles representam 39,5\% da amostra. Mas considerandose que graduandos, graduados e os especialistas compõem um grupo que não está cursando ou concluiu um curso de pós-graduação stricto sensu, o percentual sobe para $58,1 \%$. Mestres e mestrandos representam 18,6\%, e doutores e doutorandos representam $23,2 \%$. Se considerarmos os mestres e doutores em um único conjunto indicativo de titulação de pós-graduação, o percentual é de 41,8\%. O gráfico 4 indica a titulação dos pesquisadores associados no momento em que estão participando do PIPE.

\section{Gráfico 4: Titulação do pesquisador associado no momento do PIPE}

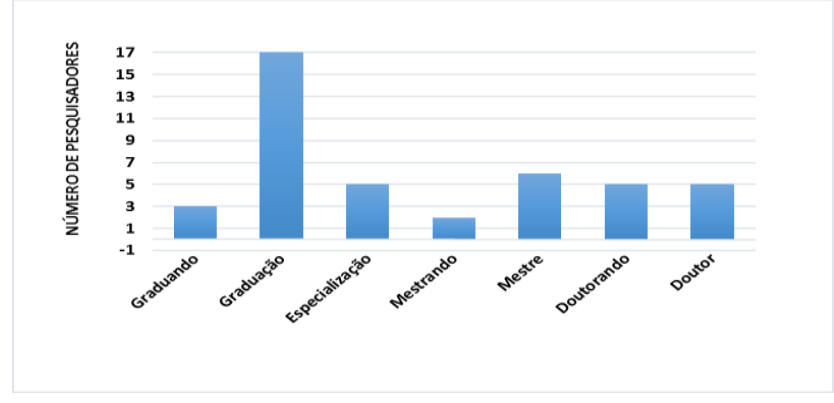

Fonte: Elaboração própria

Para se ter um significado mais preciso sobre este resultado é preciso cruzar esta informação com o curso de graduação/especialização/pós-graduação cursado, especificando a área de formação dos pesquisadores. Deste modo é possível identificar se a formação está relacionada a cursos afins da computação ou a cursos de áreas relacionadas aos usuários finais dos SI (educação, saúde, agricultura...). Isto será feito no próximo item.

\subsection{Qual a trajetória acadêmica dos pesquisadores que participam do PIPE?}

O que primeiramente chama atenção é o grande número de pesquisadores responsáveis proveniente de cursos de graduação em diferentes modalidades de engenharia, eles representam $42,4 \%$ da amostra estudada. Este fato pode indicar que os cursos de engenharia se propõem a formar pessoas com capacidade para resolver problemas, fato que pode potencializar o interesse dos engenheiros por inovação 
tecnológica em maior intensidade do que formações mais acadêmicas e menos pragmáticas. Um "segundo grupo" é aquele formado por graduações relativas a computação ou cursos de graduação em que a computação é parte da formação. Aqui temos os cursos de Ciência da Computação, Informática Biomédica, Sistemas da Informação, Física e Matemática. Estes cursos representam a origem de formação de $33,3 \%$ dos pesquisadores responsáveis. Considerando apenas os cursos diretamente relacionados a computação, isto é, os cursos de Engenharia da Computação, Ciência da Computação, Informática Biomédica, e Sistemas da Informação verifica-se que eles são a origem de formação de $42,4 \%$ dos pesquisadores responsáveis. Um "terceiro grupo" é formado por graduações que guardam relação com os temas que serão pesquisados em cada projeto. Neste grupo estão os cursos de graduação em Administração, Artes Visuais, Biologia, Ciências Sociais, Eng. Agronômica, Eng. Florestal, Música e Oceanografia. Estes cursos representam a origem de formação de $24,2 \%$ dos pesquisadores responsáveis.

Estes resultados indicam que além dos conhecimentos em Computação, os pesquisadores responsáveis precisam conhecer bem a área específica para a qual o SI está sendo desenvolvido. Este é um forte indicativo do papel central que os usuários finais desempenham nas decisões sobre os diferentes aspectos de um SI, entre eles: a arquitetura, as funcionalidades, as interfaces, a usabilidade, as possibilidades de construir conhecimento e de subsidiar decisões. O gráfico 5 apresenta o curso de graduação do pesquisador responsável.

\section{Gráfico 5: Formação na graduação do pesquisador responsável}

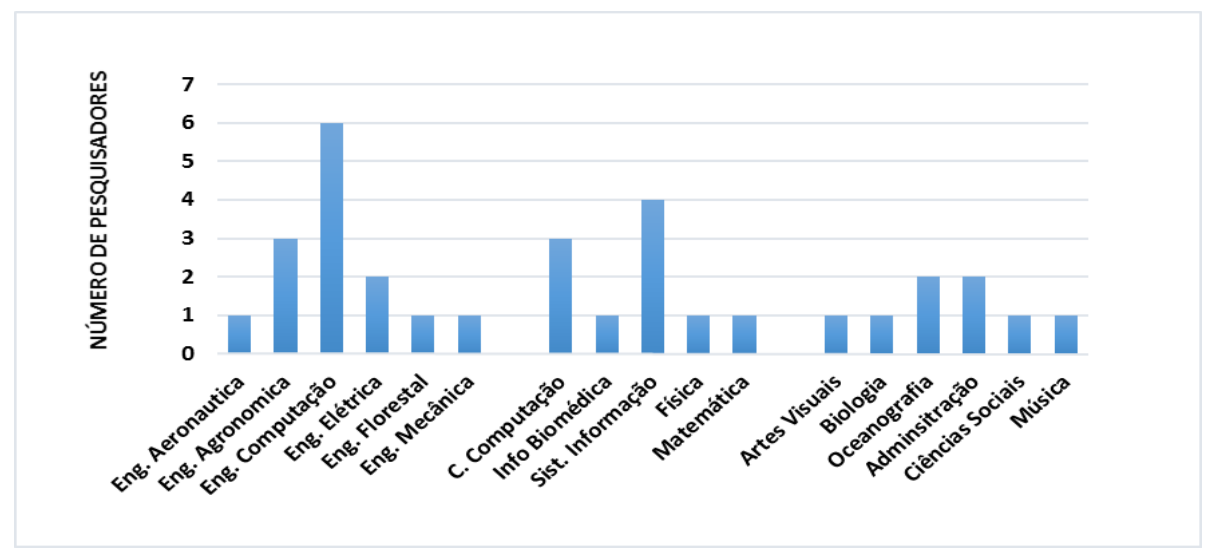

Fonte: Elaboração própria.

É importante relembrar que, no momento em que participam do PIPE, 64,7\% dos pesquisadores responsáveis já são mestres e doutores ou estão cursando a pós-graduação para obter estas titulações. Focalizando a atenção nos cursos de mestrado e doutorado, e considerando aqueles que estão cursando ou já concluíram em um único grupo, verificase a forte presença do curso de Ciências da Computação na complementação formativa de 39,1\% dos pesquisadores responsáveis. Por outro lado, tem-se uma grande dispersão em diversos outros cursos cuja base formativa não é a computação. Alunos de cursos de pós-graduação como: oceanografia, clínica médica, música, recursos florestais, administração, agronomia, educação, física, engenharia elétrica e informática na saúde até podem fazer uso rotineiramente de programas de computador e deles obter vários benefícios, mas não recebem ao longo do curso formação específica para desenvolver 
protótipos de SI em suas áreas de atuação. O gráfico 6 indica qual a formação obtida na especialização e pós-graduação do pesquisador responsável.

\section{Gráfico 6: Pesquisador responsável: formação na especialização e pós-graduação.}

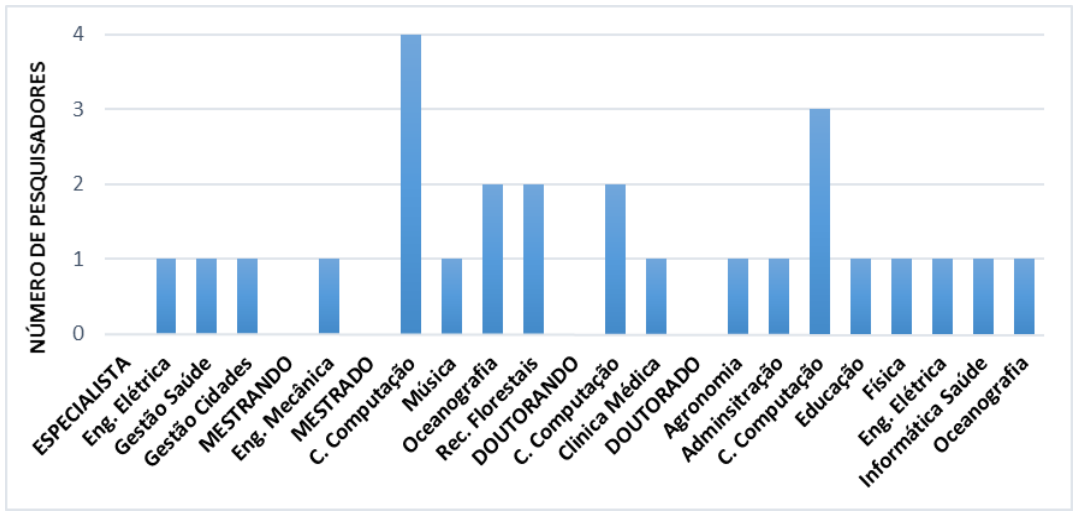

Fonte: Elaboração própria.

Outro percurso formativo a ser considerado é o dos pesquisadores associados. Podemos, a partir desta informação, tentar esclarecer se o papel desempenhado por eles é o de auxiliar o pesquisador responsável, que divide parte de suas tarefas com os pesquisadores associados, ou se eles agregam habilidades e competências diferentes de quem lidera o projeto. Cabe relembrar os resultados do item 4.4, sobre a titulação dos pesquisadores associados no momento de sua participação no PIPE: $58,1 \%$ são graduados ou possuem especialização; $18,6 \%$ são mestres e mestrandos; $23,2 \%$ são doutores e doutorandos.

A tendência aqui é bem definida, cursos de graduação relacionados a computação como Ciência da Computação, Sistemas de Informação, Sistema Web, Informática Médica e Engenharia da Computação é a formação básica de $80,0 \%$ dos pesquisadores associados. Nas graduações em que fundamentos da programação de computadores se faz presente como Física, Engenharia Elétrica e Engenharia Mecânica tem-se 10,0\% dos pesquisadores associados. Nas outras graduações, como Administração, Economia e Odontologia tem-se $10,0 \%$ dos pesquisadores associados. O gráfico 7 indica o curso de formação na graduação do pesquisador associado.

\section{Gráfico 7: Formação na graduação do pesquisador associado}

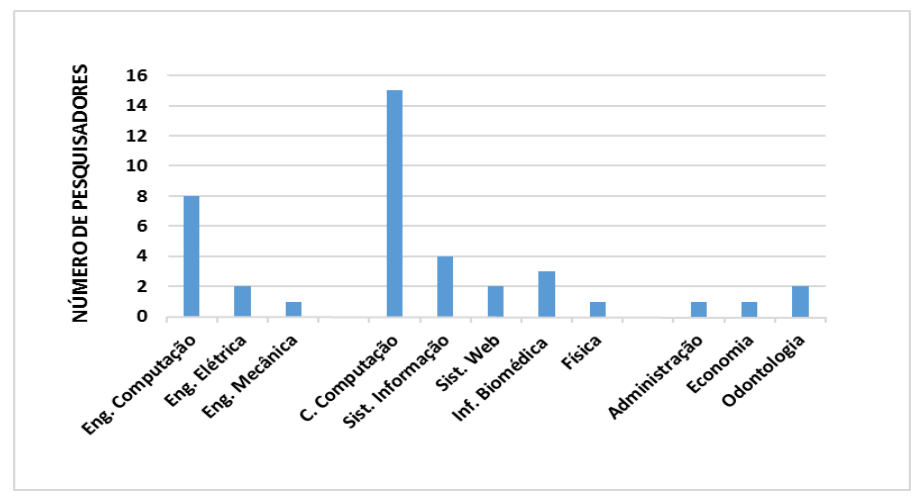

Fonte: Elaboração própria. 
A continuidade do percurso formativo se estende para além da graduação em cursos de especialização lato sensu e nos cursos de pós-graduação strictu sensu. Deste modo, é necessário investigar também esta etapa de estudos. Focalizando a atenção nos cursos de mestrado e doutorado e considerando os cursos específicos para formação em computação como Ciências da Computação e Bioinformática verificamos que 55,5\% dos pesquisadores associados se enquadram neste perfil formativo. Nos cursos em que competências em computação são necessárias, como Engenharia Elétrica e Física temse $33,3 \%$ dos pesquisadores associados. Em cursos sem grande proximidade com a computação como, Bioenergia e Ciências Médicas tem-se 11,1\% dos pesquisadores associados. Fica bem caracterizado que os pesquisadores responsáveis escolhem para seu projeto pesquisadores associados com competências em computação ( $80 \%$ dos graduandos e $88,8 \%$ dos pós-graduandos). É importante ter em mente que o desenvolvimento de um SI segue algumas etapas essenciais: levantamento dos requisitos demandados pelos futuros usuários do SI; configuração destes requisitos em um programa de computador capaz de atender plenamente estes requisitos; testes do protótipo em condições reais de uso. Isto parece indicar que durante a fase de levantamento de requisitos, pesquisadores sem formação específica em computação podem ser requisitados, mas nas etapas de desenvolvimento do sistema de informações a formação em computação se torna indispensável. O gráfico 8 indica qual a formação na especialização e pós-graduação do pesquisador associado.

\section{Gráfico 8: Formação na especialização e pós-graduação do pesquisador associado}

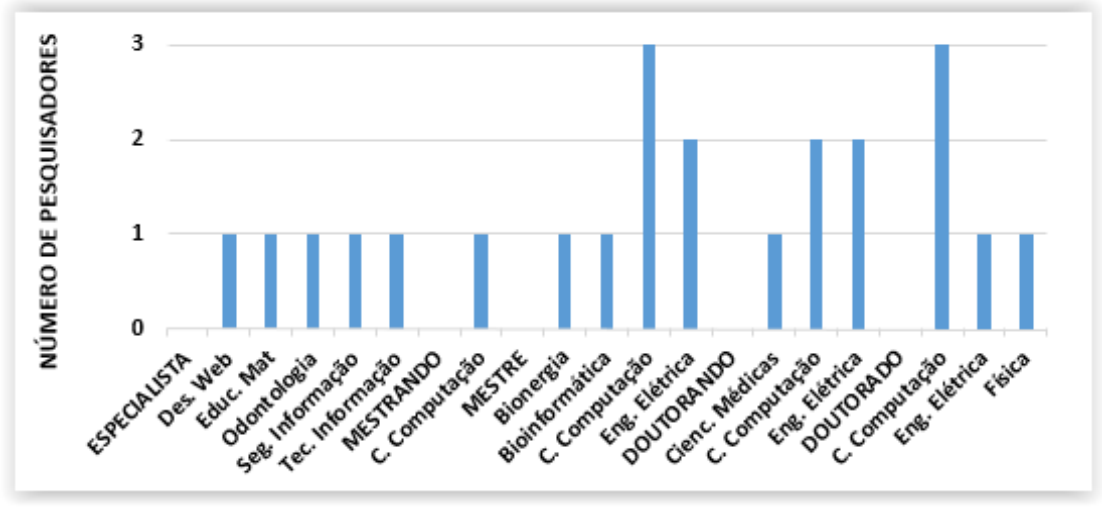

Fonte: Elaboração própria.

\subsection{Quais universidades formam os pesquisadores que participam do PIPE?}

Os resultados apontam para a grande presença das universidades públicas, estaduais e federais do Estado de São Paulo. Com grande destaque para a Universidade de São Paulo em todos os níveis formativos: graduação, mestrado e doutorado. Nesta amostra, nenhuma das outras universidades públicas, nem o conjunto de todas as universidades privadas, conseguem se aproximar da influência da USP na trajetória formativa dos pesquisadores responsáveis no PIPE em projetos inovadores de SI.

Não faz sentido justificar a hegemonia da USP no percurso formativo destes pesquisadores pelo fato da USP formar mais alunos. Mesmo reunindo todas as outras públicas do Estado de São Paulo (UNICAMP, UNESP, UFSCar, UFABC, UNIFESP, ITA, FATEC) tem-se 21 passagens formativas, contra 28 passagens formativas pela 
USP. Estaria a hegemonia da USP sendo influenciada pela proximidade física e sinergia histórica da FAPESP com a USP? As estratégias e a intensidade de divulgação do PIPE são mais favoráveis à participação da USP do que das outras universidades? Como explicar a participação inexpressiva do ITA e da participação nula da Universidade Federal do ABC, que prezam por uma formação competente em computação? A busca de resposta para estas perguntas pode auxiliar a equipe gestora do PIPE a desenvolver novas estratégias de divulgação para ampliar a participação das outras universidades públicas e das instituições de ensino privadas (existem algumas graduações muito boas na área da computação entre elas).

As reuniões de orientação aos candidatos ao PIPE, denominadas "Diálogo sobre Apoio à Pesquisa para Inovação", que ocorrem no auditório da FAPESP, não poderiam ser realizadas também em locais que favorecem maior participação de outras comunidades universitárias como: ABC Paulista, Campinas, Ribeirão Preto, São Jose dos Campos e São Carlos? Ou ainda, por que não transmitir estes encontros ao vivo pela internet, ampliando sua abrangência?

O resultado da amostra analisada não deixa dúvida sobre o papel das universidades públicas na trajetória formativa dos pesquisadores, em especial na pós-graduação. Mas se este destaque é mais do que esperado nos cursos de pós-graduação, onde as IES Privadas não se destacam, na graduação, as IES Privadas concentram a maior parte da oferta de vagas e formam mais graduandos do que nas universidades públicas. Deste modo, uma maior presença de pesquisadores inovadores em SI oriundos delas de fato poderia acontecer. $\mathrm{Na}$ amostra estudada, temos três pesquisadores responsáveis que se graduaram em IES Privadas (Análise de Sistemas - PUCCAMP, Engenharia da Computação - PUCCAMP e Ciências Sociais - PUC/SP) que lideram seus projetos mesmo sem estudos posteriores em cursos de pós-graduação. Estes casos podem ser um indicativo de que as IES Privadas podem proporcionar bons cursos de graduação que sustentam a construção de carreiras profissionais suficientemente sólidas para permitir participar do PIPE com sucesso. O gráfico 9 indica em quais universidades estudaram os pesquisadores responsáveis na graduação, na especialização e na pós-graduação.

\section{Gráfico 9: Universidades de formação do pesquisador responsável}

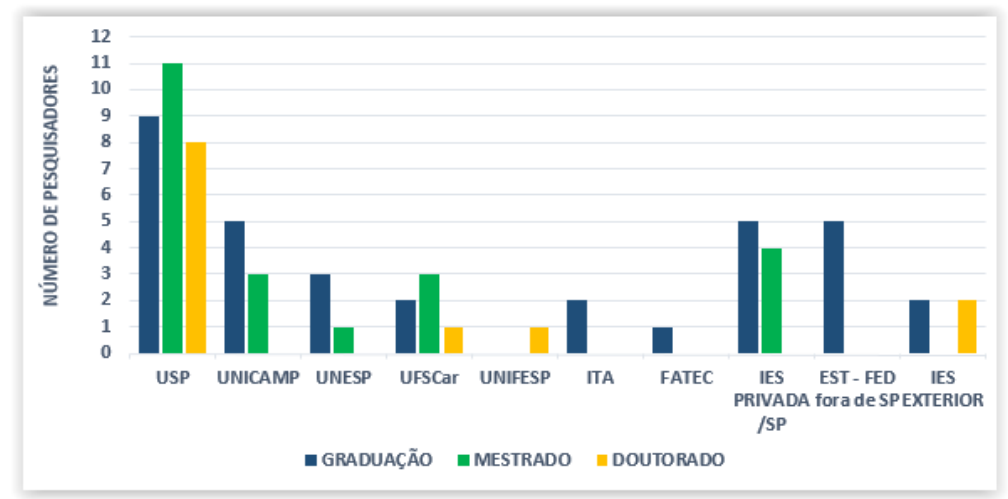

Fonte: Elaboração própria.

Verificar quais universidades contribuem para o percurso formativo dos pesquisadores pode ajudar a esclarecer duas dimensões distintas, mas complementares, 
que podem ser decisivas para fomentar o espírito inovador de seus egressos. A primeira dimensão é a qualidade dos cursos enquanto fundamento de uma boa formação acadêmica, requisito para a inovação tecnológica. A outra dimensão é a formação do espírito empreendedor em bases sólidas. Projetos Pedagógicos que adotam práticas que apoiam, ao longo do curso, o enfrentamento de desafios formam pessoas com os requisitos que tem se demonstrado determinante em grande parte das inovações tecnológicas mais impactantes.

Estas duas dimensões, amparadas pelos recursos financeiros necessários para que o projeto inovador se concretize, maximiza o sucesso das iniciativas de inovação tecnológica. Se não existem dúvidas sobre a importância da boa formação acadêmica como fator essencial na inovação tecnológica, entretanto, sobre a contribuição da formação do espírito inovador nas universidades pouco se sabe. As iniciativas de promover a formação de um espírito empreendedor nas universidades públicas e privadas são recentes e em fase de consolidação. Por outro lado, é difícil mensurar em que medida uma boa formação em empreendedorismo impacta na determinação de propor projetos inovadores para programas como o PIPE. Uma investigação possível (que não é objeto desta pesquisa) é verificar em que medida as monografias de graduação, as dissertações de mestrado e as teses de doutorado estão na fundamentação e na inspiração de projetos apoiados pelo PIPE. Este dado poderia esclarecer em que medida os trabalhos acadêmicos estão alinhados com a perspectiva da inovação.

Passa-se agora a analisar o percurso formativo dos pesquisadores associados. Verifica-se que este percurso é similar ao dos pesquisadores responsáveis. A hegemonia da USP é ainda mais acentuada aqui, enquanto temos 31 percursos formativos na USP, nas demais universidade públicas do Estado de São Paulo tem-se 12 percursos formativos (5 da UNICAMP; 3 da UNESP; 1 da UFSCar; 3 do ITA). Mas a participação de IES privadas de São Paulo e de outros estados na graduação se torna relevante, tem-se 15 percursos formativos nestas instituições. Comparativamente, a USP está presente na graduação de 13 pesquisadores associados. Temos ainda a participação de federais de outros estados no percurso formativo de 6 pesquisadores associados. $\mathrm{O}$ gráfico 10 indica em quais universidades estudaram os pesquisadores associados na graduação, e na pós-graduação.

\section{Gráfico 10: Universidades formadoras do pesquisador associado}

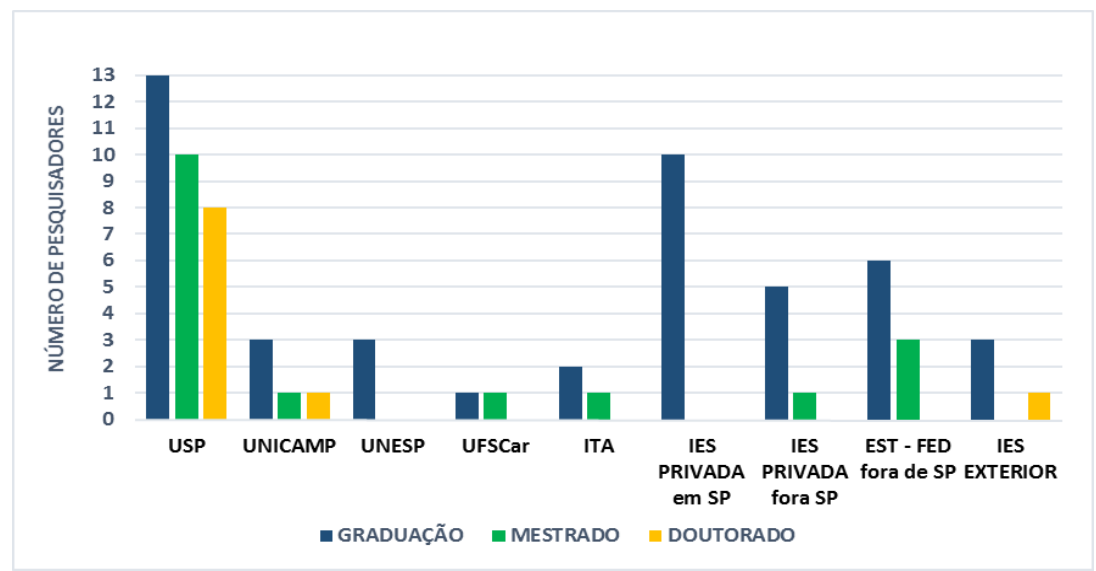

Fonte: Elaboração própria. 


\section{Considerações finais}

\subsection{Sobre os resultados deste estudo}

A intenção primordial deste trabalho foi procurar investigar elementos que tornem explícitos os múltiplos fatores que atuam no processo da inovação em SI. Quer-se identificar que fatores são estes e como se articulam, e assim obter uma análise que seja sistêmica.

Não faz sentido analisar o estágio atual do conhecimento científico e tecnológico, em particular na computação, separadamente das demandas dos usuários por novos softwares e aplicativos que permita acessar, manipular e produzir significados por meio deles. Não faz sentido analisar o papel desempenhado pelo saber adquirido pelas pessoas (acadêmico e advindo de suas vivências profissionais) separadamente dos fatores subjetivos que impulsionam a criatividade. Demandas sociais, conhecimento científico, empreendedorismo e economia criativa, é na conjunção destes fatores que se produz a inovação em SI.

Em recente reflexão sobre as políticas de ciência e tecnologia, Monteiro (2015) chama atenção para a necessidade de reflexão sobre os desencontros existentes na concepção dos programas e iniciativas de apoio à ciência e tecnologia e na forma como na prática elas acabam acontecendo. Monteiro termina sua reflexão com as seguintes considerações:

Investir na compreensão mais qualitativa da construção de políticas de CT\&I na prática é assim uma forma de promover não somente uma reflexão mais crítica e rica dos processos que ajudam a orientar a formatação de tais políticas, mas de oferecer ferramentas para a avaliação e possível reorientação de políticas de forma a que se tornem mais efetivas, mais democráticas e sustentáveis no longo prazo.

O PIPE e outros programas de apoio à inovação tecnológica tem obtidos resultados importantes que ajudam na reflexão sobre as estratégias de suporte ao ímpeto inovador daqueles que formatam projetos inovadores e dependem de custeio para avançar na execução destes projetos. As instituições, como a FAPESP, e outras que concebem e executam estes programas certamente refletem sobre a sua execução de seus programas de apoio à inovação e utilizam estas reflexões para aperfeiçoar, substituir ou cancelar o modelo que está sendo praticado. No entanto, muito pouco destas reflexões tem se tornado pública para que seja compartilhada com outros interessados nos projetos de apoio à inovação. Deste modo, um diálogo franco, aberto e propositivo sobre os caminhos e descaminhos destes projetos de apoio à inovação fica restrito nas instituições entre as suas equipes gestoras.

É possível que exista, por meio de uma rede de contatos pessoais, troca de informações entre gestores de diferentes programas de apoio à inovação, e por meio desta rede privada circulem informações que acabam determinando uma evolução mútua destes programas. Entretanto, ainda não se observa uma rede de aprendizado aberta em que as avaliações destes diferentes programas circulem livremente 
abastecendo e acelerando as trocas que favorecem o amadurecimento de cada programa e do sistema de inovação como um todo (seja em políticas públicas, seja em iniciativas privadas).

Um exemplo de avalição interna da FAPESP a respeito do PIPE é a recente parceria estabelecida entre a FAPESP e a Royal Academy of Engineering que permitiu enviar 23 coordenadores de projeto do PIPE (Fase1) à Inglaterra para cursos de duas semanas para que eles recebessem capacitação em empreendedorismo e comercialização de produtos tecnológicos. É um reconhecimento de que uma melhor capacitação em negócios inovadores nem sempre se faz presente entre aqueles que desenvolvem projetos apoiados pelo PIPE (OLIVEIRA, 2015).

Outra iniciativa recente também reforça esta perspectiva. Em 2016, a FAPESP iniciou o "PIPE High-Tech Entrepreneurial Training" em colaboração com a George Washington University (GWU), dos Estados Unidos. O objetivo do programa de treinamento é oferecer a empreendedores já apoiados pelo PIPE capacitação na criação de negócios de alta tecnologia para que aumentem a chance de êxito em seus empreendimentos (ALLISON, 2016).

No caso específico do PIPE, enquanto um programa de fomento de apoio à inovação, existe empenho em tornar pública muitas informações relevantes sobre este programa: temos o detalhamento do funcionamento e das regras do programa; temos a divulgação das propostas aprovadas em cada ciclo; temos a divulgação da avaliação comparativa do número de solicitações e concessões do PIPE; temos os itens cadastrais dos projetos e bolsas vinculadas aos projetos na Biblioteca Virtual da FAPESP; temos a divulgação do resultado de alguns projetos PIPE em mídia impressa e eletrônica.

No entanto, aqueles que pretendem tomar o PIPE como objeto de estudo se deparam com a falta de acesso a informações relevantes: do que se tratava as solicitações não aprovadas?; considerados os parâmetros utilizados na avaliação dos projetos, quais os motivos que impediram sua aprovação (mérito, alto grau de incerteza, falta de recurso para atender todos os projetos, entre outros)?; que parâmetros são utilizados para avaliar se os projetos apoiados pelo PIPE alcançaram os objetivos a que se propunham?; os recursos investidos em cada projeto; existem indicadores para mensurar o resultado das empresas apoiadas no pós PIPE (faturamento anual; empregos gerados; melhoria no desempenho dos pesquisadores, das empresas, da coletividade em decorrência do acesso as inovações)?

Considerando estas restrições de informação, é forçoso reconhecer que os dados disponibilizados na base aberta de dados da FAPESP é um fator limitador para uma análise mais conclusiva. Entendemos que, resguardando o sigilo de informações pessoais, da empresa ou de informações específicas do projeto (que podem anular as vantagens competitivas da inovação), o acesso às informações indicadas no parágrafo anterior permitiria: maior entendimento se os percursos inovativos, daqueles que desejam empreender, estão em consonância com os objetivos do PIPE e quais podem estar em consonância com objetivos de outros mecanismos de apoio à inovação (com formatos e propostas diferentes do PIPE); aprofundar estudos sobre o PIPE e seu 
alcance; reforçar os esforços da FAPESP em dialogar com os potenciais usuários do PIPE.

A definição, pela FAPESP, de um protocolo de acesso a dados para pesquisadores é desejável e contribuiria para análises comparativas de maior alcance sobre diferentes programas de apoio à inovação. Neste sentido, acreditamos que a reflexão sobre os mecanismos de apoio à inovação tecnológica (PIPE e outros) deve ser ampla e contínua, para que, como bem destacou Monteiro, se tornem modelos mais efetivos, mais democráticos e sustentáveis no longo prazo.

\subsection{Sobre as limitações desta pesquisa}

Uma pesquisa de natureza exploratória não se propõe a generalizar seus resultados, mas antes explorar um tema particular para obter maior familiaridade de modo a tornalo mais explícito, apontar tendências, construir hipóteses.

Os resultados obtidos apontam para uma diversidade de projetos em diferentes áreas, realizados por pesquisadores de diferentes idades e de diferentes trajetórias acadêmicas. Este fato leva a pressupor a necessidade de diferentes modelos de apoio à inovação com características e formatos diferentes, visando atender a diversidade de projetos e atores da inovação.

No PIPE o pesquisador responsável precisa se dedicar pelo menos 24 horas semanais ao projeto, cuja duração prevista é de nove meses. No RHAE é preciso uma contrapartida da empresa em $20 \%$ dos recursos destinados ao projeto, os prazos de execução são maiores. São condições de contorno diferentes. Existem empresas que foram apoiadas pelo PIPE e por mais de um programa, por exemplo: pelo RHAE; pelo Núcleo de Inovação Softex de Campinas; pela Incubadora de Empresas da Unicamp (INCAMP). Este estudo não esclarece porque algumas empresas buscam e obtém apoio em diferentes programas.

Muitos projetos de apoio à inovação, foram concebidos e formatados a mais de uma década. Hoje estamos em um momento e um contexto diferente, mais complexo e de rápidas mudanças, em especial quando se trata da inserção no mercado de empresas de tecnologia da informação (TI). A formatação inicial de projetos como o RHAE, o PIPE, e de muitas incubadoras de empresas e parques tecnológicos, não vislumbravam em sua origem com o recente fenômeno das aceleradoras de empresas e sua agilidade em processos de mentoria e intermediação com investidores, buscando uma rápida inserção das start-up no mercado 9 .

O leque de opções de apoio à inovação digital se amplia e se diversifica. É preciso conhecer melhor quem está inovando em SI e verificar quais as suas necessidades e em que medida os diferentes programas de apoio à inovação estão atendendo a estas necessidades.

\footnotetext{
${ }^{9}$ Veja: “Conheça as pessoas e os lugares para quem quer empreender em SP” (NAKAGAWA, 2016), e o estudo "O Panorama das aceleradoras de startups no Brasil" (ABREU; CAMPOS, 2016). 
Este estudo verificou o percurso formativo acadêmico dos inovadores em projetos de SI, mas não verificou qual o preparo destes inovadores para empreender e transformar suas ideias em produtos e serviços a disposição do mercado.

Fica em aberto questões como: a formação de empreendedores nos cursos de graduação e pós-graduação, e como esta formação pode dar suporte à inovação em SI; quando esta formação não ocorre na academia, como os diferentes programas de apoio à inovação preenchem esta lacuna.

Outra questão relevante diz respeito a como avaliar o impacto dos modelos de apoio à inovação na: qualificação dos atores da inovação (qual a curva de aprendizado que a participação em projetos de inovação em SI proporciona a seus participantes); considerando que uma inovação de fato é uma inovação quando um processo, produto, serviço chegou ao mercado e conquistou seu espaço, quanto a participação em um programa de apoio à inovação agrega ao processo de construção da empresa inovadora e de sua consolidação no mercado; qual o impacto dos projetos de inovação em SI na economia regional e nacional (no caso do PIPE temos uma avaliação geral de todos os projetos juntos, falta uma avaliação por áreas específicas de aplicação da inovação).

Em termos de impacto econômico e social, os indicadores convencionais medem a receita das empresas e o número de empregos gerados por elas. Não temos indicadores para mensurar os ganhos sociais decorrentes do uso da inovação em SI na saúde (melhoria no tratamento médico e qualidade de vida), na educação (melhoria no aprendizado dos alunos), nos esportes (melhoria do desempenho de atletas e equipes), ou na melhoria da qualidade dos serviços públicos. Estabelecer este tipo de indicador é fundamental para que a sociedade tenha os elementos necessários para compreender o alcance e a necessidade do empenho em inovar.

Este trabalho é parte do empenho em analisar as melhores formas de apoiar à inovação em SI. Compartilhar as melhores práticas de apoio a inovação é necessário para que este aprendizado possa se multiplicar e frutificar no Brasil todo.

\section{Agradecimentos}

O autor agradece a Pró-Reitoria de Pós-Graduação, Pesquisa e Extensão do Centro Universitário Fundação Santo André.

\section{Referências}

[Abreu and Campos 2016] Abreu, P.R.M and Campos, N.M.C (2016). O panorama das aceleradoras de startups no Brasil. CreateSpace Independent Publishing Plataform, USA.

[Alisson 2016] Alisson, E. (2016). FAPESP capacita startups para desenvolver modelo de negócios. In Agência FAPESP.

[Belloni 2015] Belloni, L. (2015). Recife é o Vale do Silício brasileiro. In Revista Exame. Disponível em: http://exame.abril.com.br/tecnologia/noticias/recife-o-valedo-silicio-brasileiro . Acesso: junho 2016. 
[Bessant and Tidd 2015] Bessant, J. and Tidd, J. (2015). Gestão da Inovação. Bookman, Porto Alegre.

[Bogossian 2012] Bogossian, F. (2012). Inovação tecnológica e competitividade no Brasil. Agencia Gestão CT\&I, ABIPTI.

[BRASIL 1998] BRASIL. (1998). Lei $n^{\circ}$ 9.609. Dispõe sobre a proteção da propriedade intelectual de programa de computador, sua comercialização no país. Disponível em: http://www.planalto.gov.br/ccivil 03/leis/19609.htm (acesso julho 2016)

[Bueno and Torkomian 2011] Bueno, A. and Torkomian, A. L. V. (2011). Mecanismos de apoio financeiro à inovação tecnológica. In XVI Congresso LatinoIberoamericano de Gestão Tecnológica-ALTEC, Lima-Perú.

[Bueno and Machado 2014] Bueno, L.P.B. and Machado, T.S (2014). Exploração da interação universidade-empresa na UNIFESP. In CONVIBRA, XI Congresso Virtual Brasileiro - Administração.

[Calmanovici 2011] Calmanovici, C. E. (2011). A inovação, a competitividade e a projeção mundial das empresas brasileiras. In Revista USP, $n .89$.

[CNI 2009] CNI (2009). Inovação: A construção do Futuro. Brasília.

[Dertouzos 2002] Dertouzos, M. (2002). A revolução inacabada. Futura, São Paulo.

[Dias and Porto 2014] Dias, A. A. and Porto, G. S. (2014). Como a USP transfere tecnologia? Organ. Soc., Salvador, v. 21, n. 70.

[Gitahy 2010] Gitahy, Y. (2010). Afinal, o que é uma startup? In Revista Exame. Disponível em: http://exame.abril.com.br/pme/noticias/o-que-e-uma-startup. Acesso: junho 2016.

[Marques and Pierro 2014] Marques, F. and Pierro, B. (2014). Um salto consistente. In Pesquisa Fapesp, $n^{\circ} 215$. Disponível: http://revistapesquisa.fapesp.br/2014/01/13/umsalto-consistente/ . Acesso: junho 2016.

[Menezes and Teixeira 2013]. Menezes, J. H. and Teixeira, C. B. (2013). Resultados do RHAE Pesquisador na Empresa. CNPq, Brasília.

[MICT 2015] MICT (2015). Política de propriedade intelectual das instituições científicas e tecnológicas do Brasil: relatório Formict 2014. Ministério da Ciência Tecnologia e Inovação, Brasília.

[Monteiro 2015] Monteiro, M. S. A. (2015). Por um olhar atento à aplicação de políticas de ciência e tecnologia "no chão de fábrica". In Ensino Superior, v. 6, n. 16., UNICAMP, Campinas.

[Nakagawa 2016] Nakagawa, M. (2016). Conheça as pessoas e os lugares para quem quer empreender em SP. In Estado de S.Paulo.

[Oliveira 2015] Oliveira, M. (2015). Cursos para líderes inovadores. In Pesquisa FAPESP, n.237. 
[Paiva Júnior et al. 2014] Paiva Júnior, F. G, Martins, W.S.M., Da Silva, A.D.F, and De Santana, G.A. (2014). Empreendedor inovando o bem simbólico na rede de negócios: produção \& consumo de software no Porto Digital. In Exacta, v. 12, n. 3.

[Plonski and Carrer 2009] Plonski, G. A. and Carrer, C. C. (2009). A inovação tecnológica e a educação para o empreendorismo. In USP 2034: Planejando o Futuro / organizadores Suely Vilela, Franco Maria Lajolo. Editora da Universidade de São Paulo, São Paulo.

[Rodrigues et al. 2013] Rodrigues, F. C. R., Berbert, J. O. B., and Teixeira, M. L. F. (2013). Proteção intelectual para programas de computador: considerações acerca da possibilidade de patenteamento do software. In Revista de Direito Empresarial RDEmp, Belo Horizonte, ano 10, n. 1.

[Saraiva 2013] Saraiva, C. C. (2013). Estratégia da inovação para a empresa nascente: um estudo junto a empresas apoiadas pelo programa PIPE da FAPESP. Faculdade de Economia, Administração e Contabilidade da Universidade de São Paulo, Dissertação de Mestrado. São Paulo. 